\title{
JARDÍN Y DIÁLOGO FILOSÓFICO: PRESENCIA Y FUNCIÓN DEL LOCUS AMOENUS CLÁSICO EN EL CONVIVIUM RELIGIOSUM DE ERASMO
}

\author{
Francisco Páez de la Cadena \\ Universidad de La Rioja \\ franpaez@unirioja.es
}

\begin{abstract}
RESUMEN: Erasmo de Rotterdam (1466-1536) quiso propagar un cristianismo renovado, una nueva filosofía cristiana basada en unas Escrituras desprovistas de formalismos y alentada por la sabiduría de los antiguos. Entre las muchas obras que escribió con el fin de divulgar esta philosophia Christi, destacan sus diálogos. Entre ellos se encuentra el Ilamado Convivium religiosum (1522), que despliega los recursos propios de un diálogo filosófico renacentista. Erasmo realiza en él una suerte de emulación personal de Platón y su Fedro. Erasmo traza una compleja imitatio del diálogo platónico y lo sitúa en un locus amoenus (un lugar agradable que es la casa y los jardines de Eusebio, anfitrión del convivio), convirtiéndolo en lugar del saber y de la filosofía y, por extensión, de la moral misma, de la philosophia Christi que intenta transmitir.

De este modo, Erasmo conjuga en su diálogo un mensaje religioso con una puesta en escena verosímil y evocadora, lo que contribuye a hacer del Convivium religiosum una obra ejemplar entre los diálogos filosóficos del Renacimiento, atendiendo por igual al contenido y a su presentación dramática. En este artículo se mostrará la relevancia del jardín no solo como escenario sino como catalizador del mensaje de la philosophia Christi.
\end{abstract}

Palabras clave: Erasmo de Rotterdam, jardín, locus amoenus, diálogo filosófico, imitatio, ékphrasis, philosophia Christi.

\section{GARDEN AND PHILOSOPHICAL DIALOGUE: OCCURRENCE AND FUNCTION OF THE CLASSIC LOCUS AMOENUS IN ERASMUS CONVIVIUM RELIGIOSUM}

ABSTRACT: In his want of propagating a renewed Christianity, a new Christian philosophy based on the Scriptures devoid of formalisms and encouraged by the 
wisdom of the ancients, Erasmus of Rotterdam (1466-1536) wrote a number of works that contributed to spread his philosophia Christi, that were widely used as formative and informative texts through out Europe. Among his complex and well developed dialogues is the one intitled Convivium religiosum (1522), which displays many of the resources of a Renaissance philosophical dialogue, specially the performance of a sort of personal emulation of Plato and his Phaedrus. Erasmo traces a complex imitatio of the Platonic dialogue and locates his own in a locus amoenus (a pleasant place that is the house and the gardens of Eusebio, host of the convivium), and turns it into a place of knowledge and philosophy, and what is more, of moral itself, of that very philosophia Christi he tries to teach. Thus Erasmus combines in his dialogue a religious message and a plausible and evocative setting, which makes the Convivium religiosum an exemplary work among the philosophical dialogues of the Renaissance, equally caring for its contents and for its theatrical form. This article will show the relevance of the garden not only as a scenery but as a catalyst for the philosophia Christi.

Keywords: Erasmus of Rotterdam, garden, locus amoenus, philosophical dialogue, imitatio, ékphrasis, philosophia Christi.

Recibido: 26 de Octubre de 2016 Aceptado: 25 de Noviembre de 2016

\section{Introducción}

Una de las principales preocupaciones de Erasmo de Rotterdam (1466-1536) fue la de difundir un cristianismo renovado, reelaborado desde su propia perspectiva, la Ilamada philosophia Christi. Buena parte de sus viajes y de su labor como traductor, editor y autor estuvieron presididas por este interés divulgativo, que debe mucho a su afán de renovar la religión cristiana lo que tampoco habría sido posible sin su enorme capacidad como intelectual y escritor. Muchas de sus obras se usaron durante décadas para la instrucción de los jóvenes (entre ellas sus Adagia) y el propio Erasmo concibió otras como textos formativos, como es el caso de sus diálogos.

El valor de estos últimos es muy variado, ya que oscilan entre pequeñas escenas costumbristas en las que se expone un cierto rasgo de la vida humana, hasta obras de carácter mucho más teatral, concebidas según ciertas normas dramáticas en planteamiento, escenas y argumentaciones que permiten el desarrollo de una doctrina mucho más pormenorizada. Entre los diálogos complejos y bien desarrollados de este modo, se encuentra el Ilamado Convivium religiosum (1522), que despliega los recursos propios de un diálogo renacentista escrito por una persona culta y dirigido a otras de parecido nivel. Erasmo realiza en él una suerte de emulación personal de un autor antiguo que le sirve de leitmotiv 
y de guía en forma y fondo: se sirve del Fedro de Platón y los principales personajes de su Convivium lo evocan de inmediato, nada más comenzar la obra.

Pero Erasmo no se queda en esa simple cita, sino que traza una compleja imitatio del diálogo platónico por cuanto sitúa el suyo en un locus amoenus (un lugar agradable que es la casa y los jardines de Eusebio, anfitrión del convivio) evocando así las circunstancias del diálogo platónico, convirtiéndolo en lugar del saber y de la filosofía y, por extensión, de la moral misma, de la philosophia Christi que intenta transmitir. El roterodamo utiliza un jardín renacentista, dotado de rasgos reconocibles de la época, y lo transforma en un lugar idealizado en el que la moral se rige por normas que se hacen patentes a los invitados al almuerzo en una serie de leges que aparecen escritas en el jardín de entrada y en el acceso a la casa.

De este modo, Erasmo conjuga en su diálogo un mensaje religioso con una puesta en escena convincente mostrando entre ambos una relación verosímil y evocadora, lo que contribuye a hacer del Convivium religiosum una obra ejemplar entre los diálogos filosóficos del Renacimiento, atendiendo por igual al contenido y a su presentación dramática. Es cierto que la carga doctrinal es primordial y lastra la agilidad del diálogo, que se resiente en algunos momentos por la densidad de las argumentaciones, pero no lo es menos que el conjunto formula sólidamente la nueva filosofía cristiana que Erasmo quiere transmitir, una fe renovada, alentada por la sabiduría de los antiguos (sobre todo Cicerón) y basado en unas Escrituras desprovistas de formalismos.

Como trataré de mostrar, el jardín exhibe su relevancia no solo como escenario sino como catalizador del mensaje de la philosophia Christi; y las leges que expresan esa doctrina junto con la evocación del locus amoenus clásico hacen del diálogo erasmiano-platónico un modelo en el que el escenario natural y agradable va más allá de un mero papel metafórico y se transmuta en un actor imprescindible de una nueva manera de filosofar.

Con estas premisas, analizaré esa imitatio que Erasmo hace del modelo platónico del locus amoenus, el valor que este espacio dramático otorga a la exposición de la philosophia Christi erasmiana y, finalmente, la transformación del mismo en lugar de la sabiduría y para la moral cristiana mediante el uso de las leges horti.

\section{La inspiración clásica del locus amoenus: el Fedro platónico como modelo}

Erasmo evoca desde el inicio de su diálogo el Fedro de Platón y lo utiliza fundamentalmente para que el lector establezca una analogía entre su obra y la del ateniense aunque el contenido del Convivium es más bien de corte ciceroniano. Pero Erasmo usa esta analogía platónica para ponerse bajo la advocación de "San Sócrates" (es la exclamación literal de Nefalio, uno de los comensales). Y esa advocación comprende no solo el esfuerzo intelectual y moral de trans- 
mitir una enseñanza mediante preguntas y respuestas a la manera socrática, sino situar al diálogo en una formulación moderna del locus amoenus que se describe en los inicios del Fedro. Veamos primero cómo es este lugar idílico.

En la parte introductoria del texto platónico en la que Fedro y Sócrates charlan extramuros de la ciudad de Atenas, su conversación establece una singular relación entre el filosofar y el espacio circundante, concebido como lugar agradable ${ }^{1}$. Me parece posible e ilustrativo analizar el papel que el espacio y el paisaje tienen para los protagonistas, Fedro y Sócrates, basándose en sus comentarios: Platón hace entrar al paisaje circundante en su texto como un recurso para que los dos personajes inicien la conversación y lleguen así a ideas diversas que conducirán al asunto central del diálogo que, como se sabe, trata fundamentalmente del amor.

Fedro comenta a Sócrates que va a dar una vuelta "fuera de las murallas" (227a), añadiendo después que paseará por los caminos porque, como afirma su amigo Acúmeno "es más descansado que andar por los lugares públicos" (227a-b). De este modo nos señala que existe un adentro (el de la polis) y un afuera, el exterior a ella, dos espacios que, en este caso, estaban bien delimitados por una muralla ${ }^{2}$. Pero además de "salir al campo" (cosa que hoy nos parece muy natural y acertada), Fedro indica que no desea andar por la polis porque sus espacios son lugares públicos y prefiere estar fuera de ella. ¿Qué sentido tiene esta distinción que establece Fedro?

Quizá no nos equivoquemos demasiado si entendemos que "públicos" se refiere aquí a dos cosas a la vez. Por un lado, al carácter jurídico, al estatuto de uso de los espacios de la ciudad, que estaba suficientemente garantizado para todos los ciudadanos (calles, ágora, foro, templos eran, en ese sentido, públicos). La ciudad es, desde este punto de vista, un lugar abierto a todos. Pero por otro, creo que es evidente que Fedro alude al carácter de "visible" que tiene todo ciudadano en la polis. Un espacio democrático, cívico, es por naturaleza un espacio abierto en el que uno no se oculta, en el que ni debe ni puede ocultarse más allá de la preservación de la propia intimidad. La polis como espacio de convivencia es, conceptualmente, un espacio opuesto a la privacidad de la vivienda que escapa, por definición, a las miradas de los otros. Andar por los lugares públicos, como parece que afirmaba Acúmeno, suponía reconocer y ser reconocido. Apartarse a otro lugar que no fuera la ciudad tenía la consecuencia, por tanto, de hurtarse a las miradas de los demás, de descansar de estas relaciones y facilitar así

1. El texto en cuestión se extiende de 227 a a 230e (al inicio del diálogo) y de 278 b a 279c (ya hacia la conclusión del mismo). Utilizo Platón, Diálogos. E. Lledó et al., eds., Madrid, 1982.

2. Muchas ciudades de la Grecia clásica poseían murallas; un poco más adelante Sócrates dirá también Megara está amurallada. Para el tema de las murallas, los santuarios y la diferente apro piación del espacio por los antiguos griegos que subyace a todas estas disquisiciones del diálogo debe verse Polignac, F. de, Cults, territory, and the origins of the Greek city-state. Chicago, 1995. 
el ensimismamiento. Parece claro que ese fuera de la polis es un estar dentro de sí para reflexionar (o como en esta obra platónica, para dialogar sin interrupciones ni interferencias). ¿Cómo sería ese lugar fuera de la ciudad al que Fedro quiere salir para dejar de estar sometido a las miradas de otros ciudadanos?

En esa época las ciudades, incluso las mayores, solían ocupar una superficie relativamente pequeña e irregular, en la que los espacios habitados que se encontraban extramuros eran aldeas de unas pocas casas. Existía una variedad de fincas agrícolas de variable extensión pertenecientes a los más ricos, pequeñas parcelas de aparceros o agricultores libres $y$, como es habitual en estos casos, zonas de "transición" entre unos espacios y otros, en los que la ocupación estaba menos definida y más dispersa, dando lugar a pagos más "naturales": bosques, prados cerca de los ríos, arboledas, caminos y bardas sin cultivar próximas a ellos. Ese caminar que propone Fedro consistiría seguramente en andar por las laderas próximas a las murallas, muy probablemente sin perder de vista la Acrópolis; ni la distancia que habría que cubrir, ni el tiempo disponible para hacerlo, permiten pensar que estos personajes pensaban desplazarse a lugares agrestes o salvajes, muy alejados de cualquier núcleo de población en los que no hubiera campos en cultivo o algunos rebaños. No es difícil imaginar que ese territorio para el paseo propuesto debía componerse de espacios híbridos y heterogéneos, suficientemente poco frecuentados como para resultar adecuados para el apartamiento que Fedro requiere para la conversación o, incluso, para la soledad y la introspección, como Sócrates le insinúa3

No les resulta difícil a los amigos salir de la ciudad. En algunos sectores de Atenas se traspasaba enseguida la muralla principal, aunque en ciertas zonas hubo defensas que acompañaban y protegían todo el camino campo a través hasta el puerto de El Pireo (en línea recta, a unos 10 kilómetros de la capital). Una vez que Sócrates convence a Fedro de que le lea el discurso de Lisias que Ileva consigo, acuerdan que podrían ir "por la orilla del Iliso" (229a), el río que discurría de noreste a sudoeste hasta desembocar en la bahía de Falerón, para sentarse tranquilamente luego donde mejor les parezca. El Iliso, al decir de Fedro, es en ese punto un arroyuelo por el que sugiere avanzar mojándose los pies; ambos van descalzos y en esa época veraniega refrescarse de ese modo

3. Hoy en día, este modelo característico del urbanismo mediterráneo está irremediable mente perdido en casi todas partes. Contemplando la gran conurbación que abarca toda Atenas y los pueblos cercanos fundidos con ella (Kallithea, El Pireo, Keratsini, Peristeri, Petrupoli, Acar nes, Kifisia, Marusia, Anthusia, Pallini, Papagu, Vironas, Argiropuli, Boula, Falerón) se compren de (se ve, literalmente) que el mundo urbano socrático hace mucho que desapareció igual que el Ilisos del texto, cuyo rastro es prácticamente imposible seguir hoy, al estar en su mayor parte canalizado subterráneamente. Con todo, cualquier pueblo pequeño de habitantes en el meri dión europeo puede seguir siendo un ejemplo válido de esta sutil interpenetración ciudad cam po que retiene algo del sabor descriptivo de esta parte del Fedro. 
resulta muy agradable. Es entonces cuando Fedro señala "ese plátano tan alto" (229a) y propone sentarse a su sombra, con el vientecillo que corre y sobre la hierba existente. Sócrates corroborará a su vez que aquel lugar es un "hermoso rincón, con este plátano tan frondoso y elevado. Y no puede ser más agradable la altura y la sombra de este sauzgatillo ${ }^{4}$ que, como además está en plena flor, seguro que es de él este perfume que inunda el ambiente. Bajo el plátano mana también una fuente deliciosa, de fresquísima agua, como me lo están atestiguando los pies. Por las estatuas y figuras, parece ser un santuario de ninfas, o de Aqueloo. Y si esto es lo que buscas, no puede ser más amable la brisa de este lugar. Sabe a verano, además, este sonoro coro de cigarras" (230b-c).

He aquí los elementos paisajísticos que exhibe el diálogo platónico y lo enmarcan, permitiéndonos un análisis del espacio descrito y sus rasgos diferenciadores. En primer lugar, los elementos espontáneos en la naturaleza (árbol, manantial y prado) que se reúnen en el diálogo ofreciendo un lugar al reposo y a la conversación. El plátano (Platanus, spp.) es un árbol bien conocido y utilizado en la cuenca mediterránea como árbol de sombra, con nobleza de porte y aspecto muy atractivo en copa, tronco, corteza y hojas dando una sombra densa. Es originario del entorno mediterráneo y Oriente Medio y sabemos que en la Grecia clásica debió ser un elemento muy familiar del paisaje. Árbol y prado, con el hilo conductor del arroyo, conforman así un lugar natural que sirve de refugio en la canícula: el agua alimenta a la pradera y al árbol, conformando un espacio apetecible y fresco para el reposo; el sauzgatillo en flor proporciona sombra y perfuma el ambiente. Es de notar que no se mencionan otros árboles existentes en el lugar; la frase puede entenderse en el sentido de que Fedro se refiere al más alto de entre varios o al único que se mostraba a la vista. Pero lugares así abundan en todas las regiones mediterráneas y suele ser raro que a lo largo de un curso de agua como el que se describe aparezcan un único prado y un único árbol: si nos atenemos al hecho de que los personajes no muestran sorpresa alguna sino más bien familiaridad con lo que ven, cabe deducir sin mucho riesgo que Platón debió elegir para su descripción un cierto trecho del Iliso que conocía bien y que le resultaba especialmente agradable, sin perjuicio de que hubiera otros parecidos en los alrededores.

Sobre esta descripción de un paisaje natural, Sócrates introduce seguidamente algunos elementos que antropizan el paisaje: no solo muestran la presencia humana sino que le otorgan un carácter diferenciado y sacralizado: hay "estatuas y figuras" (230b) que convierten al lugar en un santuario. Nuestra interpretación antropológica es clara: la acción humana situando ciertos elementos transforma el paisaje natural en algo diferente, en este caso, en un espacio en el que se honra o se recuerda a ciertas divinidades. La conversación entre Fedro y Sócrates per-

4. Vitex agnus-castus, un arbusto o arbolillo mediterráneo que florece en verano. 
mite entender que no están sencillamente en "el campo", sino en un espacio situado extramuros (distinto de la ciudad) que goza de cierto aislamiento y diferente conceptualmente del lugar en el que convencionalmente viven los seres humanos. Fuera de la polis, ese espacio que Fedro y Sócrates huellan pertenece originariamente a otros seres que forman parte de la mitología. Y es precisamente esa conjunción de elementos lo que parece azuzar el recuerdo vago de Fedro cuando pregunta "¿no fue por algún sitio de éstos junto al Iliso donde se cuenta...?" (229b) a modo de indicación de que está familiarizado con el mito aunque no conozca con exactitud otros detalles. En esta conversación al desgaire entre los dos amigos que caminan a las afueras de Atenas, me parece importante y significativo que ambos asocien a la mitología y a sus dioses un espacio natural que alberga los elementos descritos. Hay una correlación, una especie de pauta, una conjunción de rasgos característicos que dotan al lugar de las condiciones necesarias para ser el espacio de una narración mitológica: espacio y mito están indisolublemente asociados. Platón presenta esta triple relación entre topos, elementos constituyentes y suceso mitológico, formulando así literariamente una estampa que no debía ser ajena a los habitantes de la Grecia clásica: un lugar campestre vinculado a los dioses o héroes, un espacio fuera de las ciudades que carecía de la jerarquización espacial propia de los templos urbanos pero que era suficientemente identificable como para expresar a cualquiera su carácter sacralizado. Figuras y estatuas cumplen ese papel identificador aunque Sócrates añade también que hay un templo cercano (el de Agras) y "por algún sitio de ésos hay un altar, dedicado a Bóreas" (229c).

Esta triple relación da cuenta, implícitamente, de los dos tipos de espacios que los hombres reconocen. Por un lado, el lugar físico en el que se encuentran y que les es propio, dentro o fuera de la ciudad; por otro, el mitológico que acoge sucesos extraordinarios. Ambos se corresponden con dos posibles actitudes humanas: el primero es el lugar del logos, de la razón, que se muestra en el lenguaje que lo describe, analizándolo y comprendiéndolo; el segundo es el espacio del mythos, de la explicación fantástica que superpone la existencia y los hechos de dioses y héroes al paisaje real de los humanos. Si la razón avanza mediante esa ordenación que es la argumentación socrática, el mito procede mediante la narrativa, el entrelazamiento y la confusión, utilizando la invención maravillosa y una amalgama de espacios y de interacciones; según el mito es posible para los hombres penetrar en la geografía misma de los dioses. Así no sorprende que Sócrates pronuncie entonces su frase de menosprecio hacia los mitos cuando habla de las naturalezas teratológicas, diciendo que para "hacerlas verosímiles, una por una, usando de una especie de elemental sabiduría, necesitaría mucho tiempo. A mí, la verdad, no me queda en absoluto para esto" (229e).

Es posible entender esta relación espacial y conceptual, como un proceso de apropiación por parte del ser humano del entorno natural, concebido como lugar en el que se producen hechos que no son de carácter terrenal sino divinos. El proceso parte del mito, que da cuenta de estos sucesos situándolos con cierta 
precisión (en un arroyo, por ejemplo); seguidamente la imaginación popular atribuye a ciertos lugares conocidos una relación directa con un suceso. En un paso posterior, para celebrar o rememorar ciertos mitos, advertir de la importancia de un lugar o, incluso, para compensar la invasión que el ser humano ejercita sobre una tierra que no le pertenece, se erigen aras o templos o, como señala Sócrates, "estatuas y figuras" que están en las proximidades del plátano, conformando un santuario. Cabe discutir si la sacralización se produce en un sentido u otro: si el paisaje se sacraliza mediante alguna actividad humana elemental (por ejemplo, construir un altar) o si el ser humano "compensa" a los dioses con esa construcción elemental por haber invadido un espacio que no era suyo y que ya estaba sacralizado de antemano todo él porque es el espacio en el que se producen los hechos que narran los mitos. En todo caso, esa sacralización antrópica o compensatoria es de importancia fundamental para la constitución de las ciudades porque el ser humano detrae de esa naturaleza intocada previamente, de ese paisaje poblado por los seres mitológicos, el espacio natural que altera y convertirá en la polis ${ }^{5}$.

Sea cual sea el sentido en que funcione este proceso de apropiación, parece inevitable que los hombres mantengan una cierta distancia con esos espacios exteriores a la ciudad que, en realidad, no sólo son anómicos (no reglados todavía por las leyes humanas) sino que no les pertenecen. Y, en mi opinión, este enfoque arroja una luz algo diferente sobre la respuesta de Sócrates al unir en una misma frase bien conocida su displicencia hacia la naturaleza (en el fondo, los dioses) y su deseo de seguir la máxima délfica de conocerse a uno mismo: "Me gusta aprender. Y el caso es que los campos y los árboles no quieren enseñarme nada; pero sí, en cambio, los hombres de la ciudad" (230d). Me parece factible entender que Sócrates señala que el aprendizaje humano comienza una vez que se abandona el mythos (como explicación de hechos solo basada en las veleidades de los dioses) y una vez que el logos (como explicación racional obtenida trabajosamente empleando las capacidades propias del ser humano) se pone en marcha: o, mutatis mutandis, una vez que se abandona la naturaleza (el "estado de naturaleza", deberíamos decir con Rousseau) y se ingresa en la polis, en el estado de sociedad. El inicio de este diálogo platónico propone por tanto una dicotomía que es básica para entender el jardín en occidente: oponer la physis, el paisaje, lo intocado, frente a la téchne, la ciudad, la polis construida. Esta dualidad irresoluble que trata de transformar la naturaleza para ponerla al servicio del hombre sin que pierda sus cualidades míticas alimenta la creación de jardines a lo largo de toda la historia humana.

5. Véase Polignac, Cults, territory,..., pp. 3289. 
Este fragmento del Fedro prefigura una pauta que seguirán muchos diálogos posteriores, a siglos de distancia, incluso mencionándolo como modelo o referencia culta que permite a los personajes comprender cuál es el marco filosófico en el que se mueven: es el caso del Convivium religiosum erasmiano. El modelo, la descripción que Fedro y Sócrates componen de ese espacio sacralizado extramuros de la polis se corresponde con una variante naturalista del locus amoenus típico. Este tipo de espacio y sus descriptiones hicieron fortuna, primero en la poesía latina; luego durante la Edad Media y, a partir de la literatura italiana del Renacimiento, en toda la literatura europea de los siglos XIV en adelante. Sus derivaciones fueron múltiples. Baste citar la literatura pastoril (por ejemplo del Siglo de Oro español) o la pintura mitológica (que se prolonga en el siglo XVII en las obras de Claude Lorraine o Nicolas Poussin y que influyeron grandemente en el movimiento paisajista inglés); en unas y otras obras se reitera una y otra vez el tema del espacio sagrado de la naturaleza, de la naturaleza como morada de los dioses. Y aunque Sócrates se muestra escéptico en la intención de hacerse más sabio aprendiendo algo que el propio escenario en el que se mueve no quiere enseñarle, ese lugar sacralizado por la presencia de ninfas y dioses diversos se transforma por medio de la literatura en un espacio apropiado para dos asuntos no exactamente divinos pero sí íntimamente relacionados con los dioses: el amor y la creación poética. Estas dos actividades suponen la sublimación de los sentimientos humanos en hechos y dichos, respectivamente. Los temas pastoriles que darán lugar a numerosas obras poéticas renacentistas (de Petrarca a Garcilaso, de Góngora a Sannazaro) se ven o se prefiguran en el texto platónico: hombres en compañía de sus amados, de dioses y ninfas, la idea de la música en el aire acompañada del suave viento que sopla, la conversación entre amigos, las disquisiciones sobre el amor o la práctica del amor mismo. Y gracias al redescubrimiento del platonismo de la mano de filósofos humanistas como Marsilio Ficino (que inicia su De amore con la lectura del Fedro en el jardín mediceo que tuvo la supuesta academia platónica en Florencia) o a recreaciones como la de Erasmo, el hortus conclusus cristiano de los monasterios, evocador de la amada del Cantar de los cantares y del paraíso, pasa a convertirse en la literatura clásica en locus musarum, lugar de inspiración y de pensamiento, transmutado enseguida en locus amoenus, en espacio grato concebido para el encuentro de dioses y hombres en el ahondamiento de las actividades humanas más transcendentales: la poesía, el amor y la filosofía.

\section{Los rasgos esenciales del locus amoenus caracterizado por Curtius}

El filólogo y crítico Ernst Robert Curtius (1886-1956) sistematizó los rasgos del locus amoenus clásico en 1948. Curtius se ocupó primordialmente de este locus en la literatura medieval pero para su caracterización tuvo que remontarse a la Grecia clásica; de esta conjunción que explica en qué se basa la idea de 
lugar ameno, extrapolaré algunas de sus ideas ${ }^{6}$ para estudiarlo en el diálogo renacentista de Erasmo.

Homero es, inevitablemente, el primer autor cuyas descripciones de la naturaleza transmiten la idea de que tiene un carácter divino. El poeta destaca los aspectos más agradables y envolventes, como los bosquecillos con arroyos y las praderas exuberantes, relacionados con las divinidades. Las referencias a estos lugares y sus rasgos característicos en la Iliada y la Odisea son múltiples, como indican dos ejemplos bien conocidos, uno de cada obra: "Y no faltó ninguno de los ríos, excepto Océano, / y ninguna de las ninfas, que moran las hermosas forestas, / los manantiales de los ríos y los herbosos prados" o “¿Por ventura son ninfas que pueblan las cumbres del monte, los veneros del río, los prados hermosos?"7 . Homero, como los autores subsiguientes, reitera una serie de elementos comunes que configuran literariamente este tipo de espacios naturales y también divinos. La dualidad que conlleva la idea de que son morada de los dioses pero así mismo lugares fértiles que los seres humanos pueden aprovechar los convierte en admirables: "El lugar del deseo del corazón, hermoso con una perpetua primavera, como la estampa de una vida bienaventurada tras la muerte; el encantador paisaje en miniatura que combina árbol, manantial y hierba; el bosque con diversas especies de árboles; la alfombra de flores" ${ }^{\prime 8}$. Son propios de seres superiores y albergan también promesas para el hombre, ofreciéndole unas posibilidades de riqueza y de armonía con la naturaleza que los hacen sumamente deseables.

¿De qué elementos se componen esos lugares naturales y divinos que se ofrecen al hombre? En un primer momento la sombra (y, por ello mismo, los que la producen, un árbol o un grupo de árboles), un arroyo o manantial (que garantiza la presencia de agua como base de la fertilidad de la tierra) y un prado (hierba y flores son expresiones de fecundidad, al tiempo que muestran la variedad de la naturaleza y su belleza y sirven al reposo, psicológico y físico): estos rasgos son los esenciales y todos presentan una vertiente práctica, como la de combatir el calor, refrescarse (recuérdese que Fedro propone caminar por el Iliso mojándose los pies) o sentarse cómodamente. Esta combinación de poesía, naturaleza y agricultura obliga a una cierta contextualización porque si la polis ofrece rasgos eminentemente prácticos para la vida en común, basada en una organización colectiva que tiende (debe tender) a un bien general, la naturaleza y su sublimación estética son otra cosa: Curtius cree que esa transformación en descripción poética, en ékphrasis, expresa la idea de vivir naturalmente, alejado de la ciudad, cuando se desea esa combinación de poesía, filosofía y libertad. Y plantea

6. Curtius, E.R., European literature and the Latin Middle Ages. Princeton, 1990, pp. 183202.

7. Iliada, XX, 7 9; Odisea, VI, 124.

8. Curtius, E.R., European literature..., p. 186. 
así mismo que ese es el motivo por el cual los pastores, alejados obligadamente de las ciudades para cuidar sus rebaños, se convierten de modo lógico en sujetos de la poesía pastoril, con Pan por dios tutelar, con una flauta de caña para expresar sus sentimientos y mucho tiempo libre y soledad en abundancia a su disposición. Exactamente lo opuesto a lo que se vive en las ciudades: el agobio de las ocupaciones, la falta de tiempo, las prisas, la sujeción a unas reglas de convivencia. Curtius viene a decir que la música y la poesía exigen, y surgen, de un apartamiento que es a un tiempo reposo y despreocupación (otium) y significa de raíz una opción vital opuesta a la vida comunitaria de la polis basada en el interés y en el negocio (el nec-otium, la negación del ocio).

No cabe dudar, a la vista de los testimonios literarios, de que en la Grecia clásica cuajó esta asociación aunque no es descartable que su origen sea mucho más antiguo. La oposición naturaleza-ciudad es ancestral y obligada (esa conquista del espacio de la naturaleza para constituir la ciudad representa la esencia misma de la civilización), lo mismo que la oposición entre agricultores y ganaderos en muchas culturas, cuya estampa más conocida y significativa es la bíblica presentación de frutos a Yahvé por parte de Caín y Abel: es del pastor Abel de quien Yahvé recibe los primogénitos del rebaño y su grasa mientras que los presentes del agricultor Caín no los ve con buenos ojos ${ }^{9}$. Resulta significativo que Curtius atribuya a esto uno de los leitmotiv del género, según el cual la poesía pastoril "redime" en cierto modo la maldad de Caín por asesinar a su hermano: estos modelos pastoriles lírico y épico cuajan a partir de Teócrito de Siracusa (310-260 a.n.e.) y Curtius los tiene por los más influyentes y perdurables de todas las literaturas hasta la época moderna. La vida pastoril está generalizada en todas las culturas mediterráneas y ello proporciona un sustrato común de temas y experiencias, como la observación de la naturaleza y de sus fenómenos, la compañía de los animales, la soledad anímica del pastor, la música sencilla que hace él mismo y le acompaña en sus horas solitarias, generalmente producida por instrumentos fabricados personalmente, o el anhelo de compañía de mujeres y amigos. Curtius observa un paralelismo entre estos escenarios naturales en los que viven y poetizan los pastores y la idea de un paisaje mítico concretado en la Arcadia $^{10}$.

La lírica renacentista, con su recuperación humanista de temas clásicos, rescató la pastoril pasando obligadamente por Virgilio quien asumió el legado griego, practicó este tipo de poesía y lo transformó con los elementos y las claves que se verán en otros poetas más de diez siglos después. De las ideas virgilia-

9. Génesis 4, 27.

10. Curtius, E.R., European literature..., p. 187. Añade Curtius que determinados aspectos de la poesía griega contribuyeron a la fijación del género. Por ejemplo, la presencia de vaque ros o boyeros de cuyo nombre griego (ßоvкодós) procede el vocablo "bucólico", asociado a la lírica pastoril. 
nas, una primera fue la conversión de Sicilia, escenario natural de la poesía pastoril griega, en un equivalente de la Arcadia griega, transmutación que rápidamente pasó a formar parte del elenco mítico de la poesía en lengua latina y, luego, de la renacentista. La segunda metamorfosis de importancia fue la cronológica, situando el mundo pastoril en la historia coetánea, o casi, de la Roma de entonces. Para Curtius la poesía virgiliana proporciona claves esenciales, sobre todo la primera égloga, que introduce "el motivo del reposo bucólico" que se repite en las otras. No deja de resultar significativo que la Égloga I presente el tema bucólico del pastor Títiro que vive en el campo cuidando sus rebaños ("recostado tú bajo la fronda de una extendida haya ensayas pastoriles aires con tenue caramillo"11) como contraposición a las desgracias del exilio que le expone Melibeo: la lírica pastoril (con su trasfondo de naturaleza amable y no antropizada) no queda entonces simplemente como un marco bello o como un modo despreocupado de pasar la vida, sino también como una opción radicalmente diferente y posible frente a la civilización, que lleva a perder las propiedades e incluso al destierro.

Virgilio sintetiza además los dos modos clásicos (antitéticos, complementarios) de abordar el paisaje que serán comunes hasta bien entrado el siglo XVII: en ese momento se vivirá un cambio con la aparición de la pintura paisajista holandesa, que proporcionará realismo, temas y perspectivas profanos muy distintos de gran influencia en la jardinería inglesa y europea hasta el siglo XIX. Esos dos enfoques virgilianos reciben su nombre de sus dos obras temáticas, bucólico y geórgico. Si el primero es lírico, como ya se ha visto, y se desarrolla en el escenario de un paisaje idealizado, situado por lo general en una región mítica, el segundo está literalmente pegado a la tierra, es netamente agrario y productivo y busca el provecho por medio de un cultivo racional, sabio y en sintonía con la naturaleza. Los cuatro libros de las Geórgicas están bajo el signo de la fertilidad, que no nace de la contemplación arrobada sino del trabajo cumplido con esfuerzo. Y aunque el espacio agrícola esté poblado de faunos, dríadas y ninfas, y las invocaciones a dioses mayores (Pan, Minerva, Neptuno) sean continuas, su contenido literario no son las alabanzas a los campos ni el canto de los amoríos entre pastores sino el relato más o menos técnico que sirve para que la tierra nos sea propicia y otorgue sus dones: es una sintonía espiritual, al tiempo que práctica, la que Virgilio ensalza, y la primera, que convierte su tratado en poesía, no le impide recomendar en la segunda las artes del buen agricultor, que sabe cuándo roturar y estercolar, conoce las tierras y su vocación de cultivo, identifica a los enemigos más frecuentes y sabe cuándo aparecen los primeros brotes, cuáles son los retoños de los árboles que dan buena madera o el momento en que las abejas

11. Virgilio, Bucólicas I, 13. 
ofrecen su miel. El texto de Virgilio es, así, el cuño a partir de la cual crearán sus obras innumerables versificadores de los tiempos siguientes.

Y será también el poeta de Mantua el que introduzca, con fortuna, la expresión que, en adelante, se usará para definir la "naturaleza bella". En el libro VI de la Eneida aparece una descripción de los campos Elíseos caracterizados por la presencia de una naturaleza de carácter amable y acogedor: "deuenere locos laetos et amoena uirecta fortunatorum nemorum sedesque beatas" ("Ilegan a lugares alegres y amenos, a los campos de bosques afortunados, hogar de los benditos"). Y de ahí la expresión locus amoenus ("lugar agradable") que es modelo en la poesía medieval, según Curtius: "el bosque mixto y el locus amoenus (con praderas floridas ad libitum)", que termina por convertirse en concepto bien establecido en dos momentos distintos, el de la retórica antigua tardía y el de la muy posterior dialéctica del siglo XII, dos ramas de la gramática clásica que, por medio de una intelectualización que sistematizó los elementos fijos del locus amoenus, desarrolló una serie de topoi claramente distinguibles. Aunque no es una afirmación exenta de polémica, Curtius sostiene que la retórica judicial, entre los muchos argumentos circunstanciales que tenía que aportar como pruebas, registraba uno en concreto, el argumentum a loco, que suponía la descripción o ékphrasis pormenorizada del lugar donde habían ocurrido los hechos juzgados. En ello abunda la oratoria, especialmente como eulogía; y entre las cosas laudables, los lugares forman una categoría por sí mismos: "se los puede alabar por su belleza, por su fertilidad, por su salubridad"12.

Si lo anterior explica la génesis y el concepto, otro de los aspectos característicos del locus amoenus es cómo se transfiere al mundo de la palabra: este lugar ameno pasa a la literatura mediante la enumeración, más o menos pormenorizada, de los rasgos que lo caracterizan. El término que se aplica comúnmente a esta operación enumerativa es, ya se dicho, el de ékphrasis, que en la retórica de los antiguos vale por "descripción". Su origen es, como casi siempre, impreciso, pero en los Progymnasmata del retórico Hermógenes de Tarso (160225) uno de los ejercicios propuestos era precisamente el de describir, de componer una ékphrasis que consiguiera un efecto visual tal que pusiera literalmente ante los ojos lo que debía mostrarse, aquello que debía destacarse del discurso. Ekphráseis posibles, por lo tanto, hay múltiples porque son muchas las cosas pueden mostrarse al oyente en el desarrollo de un parlamento, desde aspectos emotivos o psicológicos hasta meras apariencias superficiales.

El procedimiento no podía serle ajeno a Erasmo ya que fueron muchos los humanistas que intervinieron en el desarrollo de esta descriptiva, una vez extraída ya de su contexto puramente retórico: baste recordar a Guarino de Verona con su traducción de la Calumnia de Apeles de Luciano de Samosata (1451), Alberti

12. Curtius, E.R., European literature..., pp. 193194. 
en muchas de sus apreciaciones en De pictura (1435-1436) y, por supuesto, a Petrarca, quien en algunos de sus sonetos o en su ascenso al monte Ventoux, utiliza términos que recuerdan este tipo de descripciones ${ }^{13}$. Castelli indica que la ékphrasis se nutrió de la varietas, proporcionando una asociación fértil, sin la cual resultaba imposible "describir y narrar"; ejemplos notables son Ficino y Poliziano con los cuales entra la ékphrasis en filosofía y poesía de manera consciente, utilizando con pleno conocimiento esa diversidad de temas posibles y que, en el caso de la naturaleza, suponen una enumeración cuidadosa de elementos pautados, concebidos como imprescindibles para la formación correcta de la imagen y, por ende, del concepto. En este sentido, una aportación interesante es el carácter completo (conteniendo lo opuesto) de esta descripción literal de lo visto: Castelli señala que "lo bello hospeda lo igualmente bello, pero uno y otro pueden ser presagio de peligros; el horror y lo feo, conjuntamente, son igualmente indicadores de peligros", de donde se deriva para la ékphrasis no solo la capacidad descriptiva de lo hermoso sino también su capacidad delimitadora, su uso como alegoría de peligros entrevistos y, en general, como base para el desarrollo de la fantasía. Y así pasa este concepto a la pintura del Cuatrocientos y del Quinientos, a caballo siempre de los textos relativos a las artes ${ }^{14}$.

Me parece importante insistir en que, para comprender la ékphrasis y su relevancia en relación con el locus amoenus, la fórmula descriptiva se refiere a todo tipo de "circunstancias" y por lo tanto no se limita solo a lo visible sino también a lo invisible: una ékphrasis digna de tal nombre se ocupa no solo de la descripción espacial precisa de los elementos que aparecen en el cuadro de visión, sea pintada o imaginaria, sino también de intangibles tales como los estados de ánimo, el tiempo atmosférico o el paso del tiempo cronológico. Pietro Aretino (1492-1556), en una famosa carta sobre la Anunciación de Tiziano describe la salutación sonora del ángel ("Ave") y el porte majestuoso, el continente celestial de la Virgen al recibir la nueva. De modo que las ekphráseis que el Convivium religiosum de Erasmo alberga y que se verán enseguida, deben entenderse desde un punto de vista global para contribuir a situar a los personajes y al propio lector, pero también (y en relación con las conclusiones que debe sacar quien lo lee) desde el punto de vista interior, que abarca el transcurso del tiempo y los vaivenes anímicos de los personajes. Son significativas en este sentido las menciones de las horas del día, los estados atmosféricos (la bruma, el calor), las alusiones al sentir de los personajes en relación con el ambiente o la referencia a los gestos concretos que completan la visión que tenemos

13. He tratado de poner al día el sentido paisajístico de esta ascensión en Páez de la Cade na, F. "La conversio de Agustín en las Confesiones traducida por Petrarca como una imitatio humanista. Una lectura de su polémica carta del Ventoux (Fam. IV, 1)”. Ecozon@, vol. 5, n 1, 2014, pp. 1132.

14. Castelli, P., La estética del Renacimiento, J. A. Méndez, trad., Madrid, 2011, pp. 127145. 
de cada escena y que suman un componente imprescindible para entenderla; muchos de esos gestos se refieren a minucias tales como los platos que se les presentan o las pequeñas obras de arte que componen el locus del anfitrión Eusebio, como también las reacciones de los personajes, la viveza de sus respuestas o su sorpresa ante determinados argumentos. Téngase en cuenta que, como tal tratado formativo y filosófico, el diálogo erasmiano no tendría por qué dejarse llevar por estas sensaciones contingentes; y, sin embargo, el espacio sensorial dibujado de este modo motiva las reflexiones o las explica. Erasmo parece hacer hincapié en que para llegar a lo inteligible se parte de lo sensible: y una gran parte del interés filosófico de su diálogo no consiste solo en la teoría que presenta sino en cómo se accede a ella. La fórmula del diálogo y la utilización de las ekphráseis es la que permite vincular ambos extremos del conocer, ir de lo sensible a lo inteligible.

A partir de Virgilio se produce un cambio que convierte el bosque mixto idealizado, adecuado para las escenas de corte épico, en objeto de descripción consciente que sirve para mostrar la maestría del poeta. Ovidio, por ejemplo, tiende a mostrar la naturaleza como un escenario mágico en el que los personajes aparecen como por ensalmo haciéndonos creer que la naturaleza posee esa fuerza oculta capaz de modificar su aspecto y nuestra existencia sin previo aviso: "De sombra el lugar carecía; parte en la cual, después que se sentara, / el vate nacido de los dioses, y de que sus hilos sonantes puso en movimiento, / sombra al lugar llegó: no faltó de Caón el árbol, / no bosque de las Helíades, no de frondas altas la encina, / ni tilos mullidos, ni haya e innúbil láurea, / y aveIlanos frágiles y fresno útil para las astas, / y sin nudo el abeto, y curvada de bellotas la encina / y el plátano natalicio, y el arce de colores desigual, / y, los que honráis las corrientes, juntos los sauces y el acuático loto, /y perpetuamente vigoroso el boj y los tenues tamariscos, / y bicolor el mirto, y de sus bayas azul la higuera"15. Del mismo tenor son muchas descripciones de la naturaleza desde la época del imperio romano hasta el siglo XVI, lo que abarca en la práctica el medievo y todo el Renacimiento. La diferenciación que se observa, según las obras, debe calificarse más bien de intensificación y especialización, de producción de un locus amoenus descrito cada vez más vívidamente, conservando sus rasgos principales y añadiendo otros en función de la época y las necesidades de cada autor. Como se verá en Erasmo, esta especialización concibe el lugar ameno como un jardín interior a la vivienda, dividido en partes, con diferentes funciones y usos. Con el fin de justificarlo ante el lector como espacio dedicado a la reflexión, lo acompaña de sus correspondientes leges, un recurso renacentista, para dar sentido al simposio filosófico.

15. Ovidio, Metamorfosis X, 8898 . 
El locus amoenus termina así por designar un lugar bello que parte de lo natural pero que casi siempre está alterado de algún modo por la mano humana y que exhibe un conjunto de rasgos bien establecido: sombra, uno o varios árboles, un prado y un manantial o arroyo. Los ejemplos más completos añaden una brisa o un viento agradable, cantos de pájaros o sonidos de insectos y abundancia de flores, bien en el prado o bien distribuidas por toda la escena. Siguiendo la tradición de la ékphrasis, el locus amoenus oscila entre la enumeración más o menos normalizada de la primera época (de Teócrito a Virgilio) y la exuberancia de elementos y calificativos posteriores que Ilevaron incluso a Horacio a criticar esa acumulación. Durante la Edad Media la normalización del estilo tuvo influencia bíblica y la idea del hortus conclusus supone también la aparición de frutos en las descripciones, lo cual aproxima el huerto o el jardín a la idea de fertilidad, en la que confluyen lo bucólico y lo geórgico de los espacios cultivados. Seguramente esta idea mixta es la que permite, junto con el concepto de Arcadia, revelar también el campo cultivado, el agro, como locus amoenus, alejándose en tal sentido de la idea de un espacio necesariamente cerrado.

Los diálogos filosóficos del Renacimiento se nutren también de algunas formas de "paraíso terrenal" en las que conocimiento y paraíso se encuentran relacionados íntimamente, del mismo modo que fertilidad y jardín son términos sinónimos para muchas culturas y épocas. Platón y su Fedro son el ejemplo, pero se recuerda con frecuencia la enseñanza de Epicuro en su jardín. Partiendo de estas asociaciones, una aportación importante consiste en reflejar un modelo de jardín basado en un espacio vivido: el Renacimiento vive la aparición de un modelo noble que se aleja del espacio absolutamente cerrado de la Edad Media y va convirtiendo al jardín en un lugar teatralizado y culto: en este sentido, el locus amoenus renacentista ya no es una inventio lírica y una ékphrasis estilística y retórica sino que pasa a ser un lugar razonablemente real en la línea en que lo muestra el convivio erasmiano ${ }^{16}$. Y para Erasmo como para otros humanistas, esa vida feliz y plena en un entorno ameno y racional toma como inspiración principal la filosofía ciceroniana y el epistolario de Plinio el Joven en el que se describen sus villae y la vida de reflexión que en ellas llevaba.

Parece posible concluir entonces que el humanismo renacentista recoge una tradición con diversos aspectos significativos. Primero, un origen en lo más antiguo de la tradición escrita grecolatina y que, por ello, remite a modelos griegos y latinos muy caros a los humanistas. La variedad de fuentes no exige seguir una línea única para mantener la tradición y por ello se dan modelos muy variados que se pueden utilizar con objetivos distintos. Segundo, la referencia cultural

16. Un ejemplo notable, bastante bien descrito y usado para establecer un dilema entre éti ca y estética se encuentra en De la constancia (1586), de Justo Lipsio. 
clásica del locus amoenus remite a la relación con la ékphrasis retórica y por ello la utilización de especies vegetales (entre los árboles, el pino, el plátano y el laurel), la mención de vientos por sus nombres (y su alusión mitológica), la existencia de pájaros e insectos, con su murmullo o su canto o la presencia de agua, con su sonido, sus alusiones a la vitalidad, a la fuente originaria de las cosas y como metáfora del tiempo, permiten componer un marco conocido por los lectores en cualquier tipo de texto, poético, narrativo o filosófico. Tercero, y no menos frecuente, la versión agraria del locus amoenus remite directamente a un paisaje arcádico que posee en sí todas las referencias clásicas necesarias para representar el mismo papel que los jardines, aunque con sentido dramático y funcional distinto. Y, finalmente, la fusión conceptual de estos espacios simbólicos con el no menos emblemático del paraíso, compone un cuadro de utilización completo para todos los gustos y ocasiones. Curtius Ilega a señalar que hacia 1150 se añade todavía una forma más, que viene a completar este catálogo: el bosque silvestre (la "selva selvaggia ed aspra e forte" de Dante), que rescata también una parte del espacio natural, incluso ignoto, heroico o terrible, como lugar de la épica ${ }^{17}$.

\section{El Convivium religiosum: la escena y la filosofía}

El diálogo de Erasmo de Rotterdam se presenta desde un principio como evocación o imitatio de los diálogos de Platón, si debemos hacer caso a la escena inicial que motiva el convite. La obra está puesta al servicio de la exposición y no tanto de la argumentación: encontramos en ella largos párrafos, más propios de un tratado expositivo que de un intercambio de opiniones entre amigos; incluso para un escritor de la talla de Erasmo la viveza de los diálogos platónicos que le sirven de modelo debió resultarle difícilmente imitable. La diferencia con obras filosóficas equivalentes es que este Convivium religiosum dedica tiempo y esfuerzo a la introducción de los personajes, a la dispositio dramática e ideológica y a las circunstancias del diálogo, lo que subraya el valor que su autor concede a tales aspectos. Ello nos permite atribuir a dichas circunstancias un peso propio en la dramatización e, incluso, tenerlas por esenciales para el planteamiento de las ideas erasmianas. Algunos aspectos de la ambientación, la importancia relativa de los diversos personajes y ciertos cambios conversacionales están tan detallados que parecen así indicar su relevancia en la exposición de las ideas debatidas. Es el caso de los pasajes en que se habla del locus amoenus que enmarca el convivio y al que dedicaré mi atención ${ }^{18}$.

17. Curtius, European literature..., pp. 201 202. Curtius aporta como ejemplo de estas for mas negativas la afrenta a las hijas del Cid en el robledal de Corpes.

18. La edición de los diálogos de Erasmo en castellano es más bien errática. Las citas que hago remiten a la paginación de Desiderii Erasmi Roterodami Opera Omnia, 10 vols., Petri Van der, Lugduni Batavorum, 1703. El coloquio estudiado se encuentra, con los demás diálogos 
Los personajes del almuerzo son nueve, "como el número de las nueve musas" (672E) y los reúne, de forma muy platónica también, una comida amistosa. Es Eusebio quien la promueve como anfitrión y dueño de la finca y de la casa en la cual se producirá el convite. Los personajes son, además de Eusebio, Timoteo (su principal interlocutor), Nefalio, Crisogloto, Eulalio, Teodidacto, Sofronio, Uranio y Teófilo; Erasmo se sirve de estos nombres para aludir a alguna de sus características personales y dotarles así de carácter dramático en el diálogo ${ }^{19}$. Estos personajes tienen una desigual participación e importancia en el intercambio de opiniones y en algún momento asienten al unísono a ciertas afirmaciones del anfitrión Eusebio, lo que recuerda vagamente el papel de los coros en los dramas clásicos griegos. Todas las intervenciones, en general, están un tanto idealizadas: el lenguaje es culto $y$, a veces, engolado; los personajes intervienen de forma sucesiva, con pocas interrupciones a sus parlamentos y las conversaciones están lejos de lo que podemos considerar una auténtica conversación real, con viveza y simultaneidad en los intercambios.

Salvo la escena inicial, que sirve de introducción, las demás se representan en casa de Eusebio; de la primera podemos deducir que Eusebio y Timoteo pasean por el campo, a las afueras de la ciudad, como lo hacen Sócrates y Fedro en el diálogo platónico, al que aluden los personajes erasmianos en los primeros compases de sus conversaciones. El trasfondo geórgico de la reunión que se promete queda patente desde el primer momento porque Eusebio declara poseer una "heredad" cercana a la ciudad, "bien labrada" (672E) que le proporcionará los alimentos propuestos para el convite "que será de hierbas y de viandas que, como Horacio dice, no se hayan de comprar. El vino, en la misma heredad se coge; pepinos, melones, higos, peras, manzanas, nueces". Y para completar "por ventura tenemos alguna gallina de un corral que allí tengo". La invitación para el día siguiente permite centrar el convite en la discusión de cuestiones filosóficas ("filósofos somos" dice Eusebio, 672D) frente a la indiferencia de otros que se ocupan de cuestiones meramente materiales, señalándose así el tono clásico y reflexivo que se quiere dar a la reunión, imitando los diálogos filosóficos antiguos de mayor renombre.

familiares, en el volumen 1, paginado a doble columna. He manejado una edición española: Erasmo de Rotterdam, Coloquios familiares, Alonso Ruiz de Virués, trad., A. Herrán y M. Santos, eds., Barcelona, 2005. La traducción clásica del benedictino Virués (1529) es muy poco fiable porque añade pasajes aclaratorios y moralistas que no están en el original: claramente tratan de suavizar o reconducir la philosophia Christi erasmiana, probablemente excesivamente profana para él. Se han cotejado esta versión española y el original latino con el texto de la edición bilingüe y bastante precisa versión italiana de Erasmo da Rotterdam, Colloquia. C. Asso, ed., Torino, 2002. Las citas son básicamente las de la edición de Virués con algunos retoques míos.

19. Por ejemplo, Timoteo (el que ama a Dios), Eusebio (el piadoso), Eulalio (el elocuente) o Teófilo (amigo de Dios). 
El desarrollo dramático del diálogo puede escandirse en los siguientes tramos: introducción (672C-673A), llegada de los comensales a la casa (673A676C), almuerzo (676C-687C) y final (687C-689F). La parte filosóficamente más importante es el almuerzo o convivio pero las demás, lejos de ser accesorias, resultan muy informativas y clarificadoras. $Y$ aunque aparecen referencias casi en cualquier parte del diálogo, las relativas al jardín y sus elementos se presentan en la introducción, en la llegada de los comensales y en el final. En mi opinión, se muestra así que el escenario del diálogo es importante ya que se hace hincapié en que los personajes son conscientes del lugar en el que se hallan para pensar juntos. Con el fin de proporcionar una idea más precisa del diálogo y su desarrollo, describiré brevemente el contenido de estos tramos dramáticos.

En la introducción (672C-673A), Eusebio acuerda con Timoteo invitar a este y a otros amigos a un almuerzo en su casa. El leitmotiv es de tipo pastoril inicialmente; Timoteo señala que "no a todos agrada la vista de flores, de prados mullidos, fuentes o ríos" (672C), en referencia inequívoca al Fedro y, un poco más adelante, recuerda que Sócrates decía que los árboles del campo no le enseñaban nada ${ }^{20}$, a lo que Eusebio replica que la naturaleza no es muda sino que habla de la grandeza de su Creador (672D); esta idea de que las cosas "hablan" es recurrente en el diálogo, como se verá. Anticipa también la presencia de las leges horti. Y como ocurre de manera reiterada a lo largo de todo el diálogo, el propio Eusebio, personaje principal (bien podemos suponer que representa al autor), opone a esa idea religiosa otra profana: que solo comerán alimentos obtenidos de sus tierras, en una referencia compleja que menciona a Horacio, Luciano, las islas Afortunadas, los placeres de los alimentos y la existencia de árboles en su huerta (672E). Es obvio que Eusebio invita a sus amigos a los deleites materiales y espirituales de su locus amoenus: un recordatorio de que ese lugar alimenta el cuerpo tanto como el espíritu.

Cuando llegan los comensales a la casa (673A-676C), Eusebio los recibe y mientras caminan hacia el refectorio, como cualquier anfitrión que se precie, va enseñando casa, patios y jardines. Es aquí donde aparecen las descripciones de mayor interés arquitectónico y jardinero. También es en esta primera parte en la que los invitados descubren las leges horti y cuyo significado presenta mucho interés, por relacionar religión, moralidad y comportamiento social, como se verá más adelante. Los comensales debaten sobre otros asuntos, uno de los cuales es el estilo del propio jardín y las plantas que alberga: aquí Eusebio describe su propiedad y contesta a las preguntas de sus invitados acerca del significado de sus obras artísticas, como la ornamentación pictórica de las galerías que rodean al jardín.

20. Platón, Fedro, 230d. 
Una vez llegados al refectorio, tiene lugar el almuerzo y se produce la conversación filosófica (676C-687B). Los personajes se disponen en torno a la mesa tras lavarse las manos (se alude aquí a la Última Cena) y se bendice la comida, y tras comentar brevemente los primeros alimentos que se les presentan (677A) comienzan a charlar al tiempo que comen.

Los presentes van interviniendo de manera sucesiva desarrollando algunos temas. El anfitrión, Eusebio, es quien guía los intercambios y en la mayor parte de casos quien proporciona las claves del tema a debatir. Estos intercambios no tienen, desde luego, la vivacidad de un auténtico diálogo ya que hay invitados que parecen estar ausentes hasta su parlamento. Este aspecto de la dramatización permite establecer dos grupos de personajes según la longitud de sus intervenciones, el momento en que se producen y la relevancia del tema que tratan. Claramente los personajes que hablan al final son los menos importantes para Erasmo, del mismo modo que los obsequios que Eusebio reparte al término de la comida entre sus invitados parecen mostrar dos rangos entre ellos.

El contenido filosófico-religioso se desarrolla a partir de la petición de Eusebio a uno de sus sirvientes (677B) para que lea unos versículos del libro de los Proverbios, en los que se señala que Yahvé sondea los corazones y que, a sus ojos, es mejor que los sacrificios la práctica de la justicia y el derecho ${ }^{21}$. Eusebio expone su teoría de que para tener buenos gobernantes se debe elegirlos bien y controlarlos mediante una asamblea adecuada, además de estar formados desde niños de la mejor manera posible; de ese modo los reyes no se convertirán en tiranos. Una metáfora del texto que habla de las divisiones aquarum, que pueden ser violentas o suaves, remite al ánimo de los reyes que, cuando es airado, no es posible reconducir; y adaptarse a él con habilidad redunda en un daño menor que oponerse a él con violencia (677F-678A). Timoteo expresa si no habrá acaso un remedio contra la "violencia de un rey malvado" y Eusebio contesta, con buena lógica, que lo primero es "no abrir la puerta de la ciudad a un león", siendo lo segundo "moderar su poder con la autoridad del senado, de los magistrados y de los ciudadanos, de tal modo que no se pueda adentrar fácilmente en la tiranía" (678A). En su intervención, Timoteo opina que los reyes no deberían estar sujetos a las leyes humanas (678B), remitiendo a Pablo de Tarso sobre la necesidad de no juzgar a los demás ${ }^{22}$.

21. Proverbios 21, 1 3. Todo el diálogo está repleto de referencias bíblicas que, por su parte, Erasmo detalló en notas a pie de página. Sería excesivamente prolijo para nuestros propósitos enumerarlas todas.

22. Es un tema recurrente en la literatura política de la época. Erasmo puso de manifiesto sus ideas en su Institutio pero dado que sus diálogos fueron creciendo con el tiempo y mostrán dose como un instrumento didáctico de primer orden, aprovecha aquí para instruir también en relación con la formación de los príncipes. En cuanto a la división de las aguas, aparece tam bién en Maquiavelo, cuyo dominio, posible o imposible según que sean tranquilas o violentas, propone como metáfora en relación con el gobierno de la república. 
Sofronio hace en su contribución (678E) otra cita de Pablo acerca de los muchos caminos que hay para Ilegar a la santidad. En esta intervención, Erasmo utiliza un recurso dramático que repite varias veces en el diálogo y que da la impresión de producirse sobre todo en los pasajes que se adentran por un terreno excesivamente teológico, lejos de las preocupaciones auténticamente humanas: el autor corta la reiteración de sutilezas en cuestiones religiosas recurriendo, casi siempre, a Eusebio, el cual desvía la atención de lo que se habla para dirigirla a la comida que están disfrutando, mencionando los alimentos, su sabor o algún otro detalle circunstancial de menor importancia.

Teófilo vuelve al asunto mencionado al principio sobre las formas y el fondo, interviniendo para hablar sobre la piedad y el sacrificio (679B). Todo este análisis sobre la necesidad de ajustarse al espíritu de la ley o cumplir su letra, reviste una crítica implícita a los hebreos, de los que se dice que dedican demasiados esfuerzos a sus sacrificios rituales poniéndolos por encima de las esencias: "Dios mostró su desagrado con los judíos no porque observaran ritos y ceremonias sino porque se vanagloriaban de ellos y descuidaban aquellas cosas en las que Dios nos exige de un modo especial; y satisfechos en su avaricia, orgullo, posesiones, cólera, envidia y demás iniquidades, creían merecer el cielo porque en los días sagrados visitaban el templo, ofrecían sacrificios, se abstenían de los alimentos prohibidos y ayunaban con frecuencia" (679D).

Tras estos comentarios, el anfitrión pide a Eulalio que enseñe el libro de cubierta dorada que lleva consigo (680D) ${ }^{23}$. Eulalio informa a sus amigos de que es un volumen con las epístolas paulinas, de las que lee y comenta un fragmento de la primera carta a los Corintios: "todo me es lícito, pero no todo es conveniente; todo me es lícito, pero no me dejaré dominar por nada", frase que Eulalio dice no comprender. En torno a ella, Eulalio desarrolla un largo parlamento sin interrupciones en el que analiza los ejemplos que Pablo pone en su carta y que tienen que ver con el cumplimiento o no de la ley, lo que puede entenderse como una segunda parte de la conversación en torno al espíritu del cumplimiento de la ley o solo a sus formalidades. Resulta llamativo que, de forma directa, su discurso no obtiene réplica alguna y se queda en monólogo pues, como dice Eusebio al terminar, "para quien sabe proponer preguntas como tú, no hace falta que nadie le responda sino él" (681E).

Llega entonces el turno de Crisogloto, quien introduce en la conversación a algunos autores profanos, lo que da lugar a un breve intercambio sobre a quién se debe dar precedencia, si a las Escrituras o a los Antiguos (681F). El principal

23. Algunos aspectos del diálogo son muy detallistas, como los pasajes descriptivos de la casa, los jardines o las pinturas de las galerías. El Erasmo editor y amigo de editores se descubre en este comentario preciso sobre ese volumen o al señalar, más adelante, en la distribución de obsequios, de qué material (vitela) están hechos los libros que regala. 
de los Antiguos es Cicerón, de quien se mencionan las Disputas tusculanas, De la vejez, De la amistad o Los oficios, obras de las que Eusebio (que además de anfitrión, se muestra como claro mentor o guía espiritual del grupo de amigos) dice no poder leerlas sin besar el libro y venerar a esa "alma divina" (682A). Eusebio remacha su idea comparando los escritos de los antiguos con los de los modernos (recentiores) y declara preferir a Cicerón o Plutarco "antes que a Escoto o veinte más como él" (682B). Crisogloto alaba el De senectute ciceroniano y hace un breve discurso sobre la conformidad con el desarrollo de la vida tomando al cuerpo no como una morada sino como una posada provisional.

Por su parte, Uranio habla sobre Catón, que en su vejez declaraba no arrepentirse de haber vivido (682F). Entre Uranio y Nefalio se establece un breve intercambio que compara ideas y frases de Pedro y Pablo; Crisogloto señala la posible arrogancia del discurso de Catón al decir que aprecia mucho más la vida de Sócrates y la valoración que el propio sofista hace de sus obras terrenales al tomar la cicuta, tal y como se cuenta en la Apología; Nefalio remata la discusión señalando su devoción por Sócrates hasta el punto de que cuando se habla de él exclama: "Sancte Socrates ora pro nobis" (683E). Todavía Nefalio y Crisogloto se explayan algo más en relación con los rituales: según Crisogloto los cristianos viven más para la pompa y las ceremonias de los sacramentos que para su significado interior, que es lo realmente importante (684C).

Toda esta extensa y no siempre clara reflexión Ileva a Eusebio a un comentario sobre los excesos y las carencias, a hacer hincapié en la caridad necesaria para con los necesitados. Eusebio cree que no se deben dilapidar riquezas en cosas superfluas sino en aquello verdaderamente útil, oponiendo ambición y caridad, lo que le suscita un comentario acerca de las riquezas de los monasterios (685C). De un modo que no puede calificarse sino de plena actualidad, Eusebio encuentra preferible a la caridad el que cada cual disponga de trabajo y que cada ciudad mantenga a sus pobres; es decir, aboga por una reestructuración de la riqueza antes que por la práctica meramente paliativa de la caridad. Para concluir (685F-687C), Eusebio da paso a los Evangelios y expone el aparente sofisma de la frase "no se puede servir a dos señores" que Teodidacto resuelve no con demasiada claridad.

En este punto (687C-689E), la conversación filosófica se detiene al tiempo que los comensales se declaran satisfechos con el banquete. Eusebio pronuncia una oración de acción de gracias (recuérdese que al abandonar la pradera del Iliso, Sócrates actúa de igual modo, orando) y a continuación reparte unas preseas, adecuadas a cada uno de los comensales. Resulta ilustrativo que estos presentes sean objetos relacionados con la actividad intelectual, además de representar aspectos de la técnica de la época: hay cuatro librillos, dos relojes, una lámpara y un pequeño escritorio. El propio Eusebio los supone "más agradables que bálsamos, dentífricos o gafas" (687E). Los amigos agradecen estos regalos y comienza un breve paseo que supone el final de la visita. Eusebio muestra la galería con 
sus pinturas murales y sus correderas de cristal (vitreis fenestris), de tal modo que el espacio queda protegido en caso de mal tiempo (688C); pasan a la biblioteca donde contemplan los libros y un globo terráqueo. El jardín se disfruta desde las ventanas ad hortum domesticum y se habla también de un huerto frutal, que pueblan los pájaros. Finalmente, Eusebio se despide de sus convidados y sale para visitar a un amigo que necesita de su apoyo y compañía.

En conjunto el diálogo es expositivo y, aunque variado e interesante, se ve literariamente algo lastrado por la densidad y longitud (a veces desmedida) de las reflexiones de los comensales. Si hubiera que extraer una moraleja de él no se ve a primera vista con claridad cuál podría ser porque los temas tratados son muchos: la educación de un buen príncipe, la formulación de enseñanzas dignas de ser seguidas (con la comparación entre los autores antiguos y los autores cristianos), la valoración de la palabra de las Escrituras por encima de los rituales, la práctica de la caridad cristiana y la acumulación de riquezas... Sin embargo, hay al menos un tema que parece quedar por encima de los demás y servirles de aliento: el contraste entre las leyes escritas y la vivencia profunda de la práctica de la religión. Dicho en otras palabras, la manera de vivir adecuadamente una vida auténticamente cristiana. Erasmo, por boca de Eusebio, parece decantarse claramente por esta última opción frente a la adscripción irreflexiva a rituales y a meros formalismos. Este es, desde mi punto de vista, el hilo conductor y viene a señalar, de una manera didáctica, cómo debe ser la vida de un cristiano, eso que Erasmo denominaba philosophia Christi, y que puede concebirse sintéticamente como un ahondamiento en la manera de vivir según el verdadero sentido las Escrituras y las leyes y sin tener demasiado en cuenta los aspectos externos y rituales de la religión. Básico es también, el apoyo que proporcionan los paganos antiguos a ese vivir cristiano: las menciones a Sócrates y a Cicerón, entre otros, señalan claramente el camino en que han de conjugarse religión y filosofía, y en qué sentido Erasmo piensa que debe darse una confluencia entre vivir cristianamente y alcanzar el ideal clásico de la vita beata.

Este tema, que podemos calificar de principal, se ve acompañado por otros dos que parecen darle apoyo conceptual y filosófico, aun de forma no expresa. Por un lado, es esencial la mención reiterada a los escritos e ideas de los antiguos, que refuerzan las ideas de autenticidad y racionalidad frente al mero seguimiento de normas, ritos y formalismos. Por otro, la reiterada ékphrasis del arte y la técnica en el entorno que acompaña el almuerzo (el jardín, las pinturas, la arquitectura, el studiolo al que se retira Eusebio para pensar), parece mostrar la modernidad del mundo en que los personajes viven, señalando un modo diferente de pensar más racional, sistemático y coherente que el encontrado en las antiguas Escrituras. Ambos aspectos parecen apoyar la idea erasmiana de la philosophia Christi, es decir, que se puede vivir acorde con el cristianismo si se siguen las ideas básicas de caridad y benevolencia expresadas en las Escrituras, presididas por un auténtico espíritu cristiano, aunque de otro lado se participe de ideas paganas (el ejemplo más vivo es la actitud ante la muerte preconizada 
por Cicerón en su De senectute y de la que hablan los comensales) o se disfrute de no pocas riquezas materiales. Una clara expresión de cómo Erasmo traza con cuidado este tipo de detalles, tanto teatrales como ideológicos, en los que abunda este diálogo, y que le permiten plantear su pensamiento y argumentar a favor de un cambio de actitudes, en su tarea de pedagogo y humanista cristiano y religioso pero, al cabo, hombre de su época, consciente de los errores cometidos por la iglesia y atento a las nuevas tendencias (la Reforma, entre otras) que asediaban a los europeos de entonces.

\section{El espacio del locus amoenus en el diálogo}

En el diálogo, los jardines de Eusebio (pero también su casa, sus obras de arte o su biblioteca) están presentes a lo largo de toda la comida. Enmarcan de modo notable el debate intelectual que se ha indicado, provocan reflexiones y comentarios que ayudan al mismo y, en mi opinión, sostienen la dispositio dramática del diálogo, debiendo por ello considerarse esenciales para el mismo.

Desde el comienzo, Erasmo presenta la naturaleza como un bien preciado cuando Eusebio dice a Timoteo que se maravilla de que "algunos hombres prefieran vivir en humosas ciudades cuando en el campo todo es florido y agrada-


Sócrates prefería las ciudades ya que la naturaleza no le enseñaba nada: como ya se ha indicado, este y otros detalles nos remiten al modelo del Fedro que preside el convivio erasmiano.

Una vez formulada la invitación, Eusebio avanza una descripción funcional de su locus amoenus, indicando que harán un almuerzo vegetariano aunque no desdeña la posibilidad de preparar también una gallina de su corral (672E). Eusebio refiere aquí los frutos que pueden comer, lo que equivale a calificar el jardín por su producción agrícola aunque también menciona de pasada a las insulis Fortunatis, lo que equivale a situar su espacio productivo entre los jardines mitológicos más nombrados de la literatura clásica. No viene al caso aquí entrar en mayores matices que pueden verse en otra parte, pero el hortus de los antiguos abarcaba como concepto lo que hoy llamamos "jardín" (un espacio ornamental, dedicado al ocio y al deleite) y el "huerto" (un espacio productivo). Es una identidad que seguía vigente en el Renacimiento y que solo con la llegada del paisajismo comenzó a romperse, distanciando con mayor claridad los espacios de reposo y descanso de aquellos destinados a la obtención de un rendimiento económico ${ }^{24}$.

24. Véanse entre otros Gothein, M. L., A history of garden art. Nueva York, 1979, o Páez de la Cadena, F., Historia de los estilos en jardinería. Madrid, 1982. 
Cuando Eusebio da la bienvenida a sus invitados, y una vez que les ha mostrado el jardincillo de la entrada, los invitados pasan al interior de la vivienda, a un patio tapiado y ajardinado. A Timoteo le evoca el jardín de Epicuro (Epicureos hortos) y Eusebio explica que es un lugar todo él dedicado al placer, honesto, y que "nutre los ojos, recrea las narices y refresca el ánimo. Aquí no nacen sino hierbas aromáticas, y no cualesquiera, sino las más nobles" (674A). Nótese que se trata de una descripción fenomenológica acerca de los efectos que tiene el jardín en quien lo visita y que no se refiere solo a la estimulación sensorial sino también a su influencia sobre el estado de ánimo.

Los amigos pasan revista a las plantas del lugar, que van acompañadas por carteles con sus nombres (674A-B). Este es un aspecto llamativo en el diálogo: los objetos y los seres vivos participan de algún modo en la disposición espiritual, reflexiva y didáctica, de su dueño. Aparecerá también después en la visita a otras estancias de la casa: los objetos que posee Eusebio no son "silenciosos" sino que hablan. ¿Y qué dicen? Sobre todo, enseñan a ver, reclaman la atención del visitante y no solo la mirada distraída del que pasa al "decir" su nombre o resaltando alguna de sus características: ello sirve de estímulo al diálogo entre los presentes, anima la transmisión de informaciones y el contraste de pareceres y permite las precisiones cultas de carácter geográfico, histórico o literario que tienen que ver con los avances científicos de la época.

El hortus del que salieron los alimentos para la comida no se describe en detalle, pero Erasmo, por boca de los presentes, sí da algunas precisiones sobre cómo está distribuido y compuesto: es un rectángulo con tres caminos o galerías perimetrales, entendiéndose que el cuarto lado es el que lo une a la casa. Timoteo opina que los tres caminos le quitan mucho espacio y lo hacen menos agradable (674C). Pero un poco más adelante Eusebio explica el por qué de esta distribución: "En este camino que mira a occidente aprovecho el sol matinal; en el que mira al este, tomo el fresco de la tarde; en el que mira hacia el sur pero se abre hacia el norte, tengo refugio contra los calores del sol del mediodía" (674F) ${ }^{25}$.

Los invitados notan también que las baldosas del suelo tienen flores pintadas, lo que hace juego con las flores naturales que crecen allí (674F) y las paredes están adornadas con frescos de árboles, aves y, en la parte baja de ese friso, animales de cuatro patas. Eusebio se encarga de mostrar que cada ejemplar de cada ser vivo representado es diferente de los demás y que se trata de especies exóticas, no precisamente domésticas, porque "no merece la pena pintar gansos, gallinas y patos" (674F-675A). Los invitados repasan algunas de las especies representadas (lechuza, camaleón, camello y otras) con exclamaciones de

25. Original y traducciones no son especialmente precisos, pero permiten deducir la distri bución que se indica. Los paseos, abiertos hacia el interior del patio, estarían "mirando" por tanto a las tres orientaciones indicadas. 
asombro o comentarios de desconocimiento (Timoteo confunde al camaleón con un lagarto). Lo mismo ocurre con las plantas, que también llevan su inscripción y de las cuales se repasan rasgos, efectos y usos. No dejan de aparecer animales fantásticos, por ejemplo un basilisco, que es "no solo formidable por el veneno sino que el destello mismo de sus ojos es letal" (675D).

Erasmo muestra aquí algunos aspectos característicos de la cultura renacentista, como el coleccionismo de carácter científico o la formación de gabinetes de curiosidades; pero remite también a ciertas ideas clásicas propagadas (y bien conocidas por los humanistas) desde el mundo romano: la Naturalis historia de Plinio el Viejo como catálogo de maravillas, las pinturas al fresco en las galerías de su sobrino Plinio el Joven que alimentaron las ideas sobre los jardines romanos de los aristócratas del Imperio, los adornos que podían encontrarse en mosaicos y en muros en las casas nobles de Roma. Nada escapa a la curiosidad de Eusebio, que también dirige la mirada de sus amigos hacia una tercera pared en la que aparecen pintados "lagos, ríos, mares y toda suerte de peces extraños" (675E) además de otros animales como "el delfín, amigo natural de la humanidad, luchando contra el cocodrilo, enemigo mortal del hombre" o criaturas anfibias y marinas como cangrejos, focas, castores, pólipos u ostras $(675 \mathrm{E}-$ 676A). El catálogo de seres enunciados, su significado mitológico y el conocimiento que de ellos se tenía en el Renacimiento centroeuropeo exigiría un análisis más pormenorizado. Baste decir aquí que este tipo de cultura que aspiraba a las condiciones de un catálogo, completo y detallado, se ve en otros intelectuales de la época y forma parte del espíritu de la misma: colección y viaje, conocimiento y colección son algunas de las caras de un poliedro complejo que es expresión de ese uomo universalis característico del humanismo ${ }^{26}$.

Tras admirar estas pinturas pasan al siguiente jardín in duas divisum partes (676A): una de ellas es el jardín culinario (herbarum esculentarum) mientras que la otra es el jardín medicinal (medicarum); del primero, así lo indica Eusebio, se ocupa su mujer. A la izquierda hay un prado abierto solo con hierba verde y circundado de un seto continuo espinoso. $\mathrm{Y}$ a la derecha está el pomarium (el auténtico huerto frutal) en donde Eusebio ha plantado algunos árboles exóticos que pretende aclimatar. Eusebio señala que en el prado es donde suele pasear o jugar con sus amigos. Timoteo, de nuevo opina que son como los afamados jardines de Alcínoo (676A). Ese es el momento en que un criado les llama a comer y la visita (con la descripción) se interrumpe.

26. Los ejemplos son innumerables, pero pueden bastar dos. Michel de Montaigne tuvo un refugio en una torre de su castillo, adornada con efigies de sabios de la antigüedad y decoradas las vigas del techo con algunas de sus frases. Lipsio tuvo varios jardines y mantuvo correspon dencia con botánicos europeos, como Carolus Clusius, para intercambiar semillas y plantas. 
Pero el diálogo no concluye cuando termina la comida. Después del reparto de regalos (688C), los invitados pasan a ver algunas de lo que Eusebio, algo menos modesto que al inicio, denomina "las restantes maravillas de mi pequeño palacio". El resto de las estancias que ven son todas a cubierto pero mantienen una relación dialéctica con el exterior y los espacios ya vistos antes del almuerzo. La sala de verano tiene ventanales a tres orientaciones distintas y permite apreciar el exterior así como protegerse la lluvia o del aire, colocando unas cristaleras, o del sol, bajando unas persianas. Sus paredes tienen pinturas de escenas naturalistas con personajes bíblicos, como Herodes o Lázaro, o también históricos como Antonio y Cleopatra o Alejandro Magno. La sala alberga también algunos objetos que Eusebio aprecia mucho: un globo suspendido (sphaera pensilis) que le "permite tener delante de los ojos todo el mundo", un atlas dibujado en las paredes, retratos de los autores más insignes. Aneja está la biblioteca con un studiolo con chimenea para el caso de tener frío (688F-689A). Todos los comensales comentan y admiran esta colección de objetos que se relacionan con el saber, con el pensamiento, con la ciencia.

Todo ello permite aventurar que ese locus amoenus en el que Eusebio vive y agasaja a sus amigos es mayor que sus propios jardines: abarca su casa entera. Toda ella está pensada para el deleite y el disfrute (eso sí, como indica varias veces, honesto), dedicado a la reflexión y a la filosofía. Muestra con claridad que no puede desgajarse la alta actividad del pensamiento del bienestar corporal y de los pequeños detalles de comodidad cotidiana. El lugar, su casa, no solo contiene aquellos objetos necesarios para ello, como los libros o el globo terráqueo, sino que el espacio mismo está concebido para conseguir ese objetivo doble espiritual y material: la sala en la que se puede disfrutar de distintos ambientes según el tiempo que haga, la biblioteca con sus libros, el pequeño espacio acogedor donde escribir y pensar. Podemos estar casi seguros de que Erasmo está describiendo (seguramente modelando y completando con su imaginación) un lugar que conoció o, incluso, un modelo que podía ser habitual entre humanistas de alcurnia y con posibilidades económicas ${ }^{27}$. Y que ese modelo real le sirvió para integrar las sugerencias de los antiguos y formular un locus amoenus humanista que sirviera a sus propósitos de difundir su philosophia Christi, una nueva propuesta para vivir el cristianismo. Este diálogo, este convivio, sirven así al propósito erasmiano de transmitir ciertas ideas: la palabra, el logos, es la filosofía en marcha, la puesta en acción en un espacio específico, bien delimitado y altamente simbólico. Filosofía y jardín se conjugan de este modo en su máximo despliegue: es el hortus que alimenta cuerpo y alma en el que residen la sabiduría y la posibilidad de obtenerla y compartirla, de

27. Es posible que la casa de su editor y amigo Froben le proporcionaran algunas ideas sobre la distribución o la decoración, pero esa estructura de casa y jardín puede verse en pin turas centroeuropeas de la época. 
transmitirla y enseñarla, a semejanza de los antiguos, sirviendo así a la instancia última de vivir cristianamente en el mundo estando en el mundo y prescindiendo de los formulismos anticuados de una escolástica ya superada.

\section{Las leges hortorum: jardín y moral}

Hay un último rasgo en este diálogo que mide la importancia del espacio ajardinado respecto al mensaje que quiere transmitir Erasmo. Se trata de la presencia de las Ilamadas leges horti que aparecen el texto, advertencias o admoniciones a modo de reglas de uso que, bien seguidas, han de garantizar el acceso a un espacio singular y espiritualmente superior. Este tipo de normas era por lo que sabemos, relativamente común en los jardines del Renacimiento, pero no ha sido muy estudiado. El análisis más conocido y pionero, muy incompleto para la época que nos ocupa, se debe a Coffin, que estudió con cierto detaIle estas leyes y el acceso a los jardines del Lazio en la época del Renacimiento ${ }^{28}$.

La investigación de Coffin se refería al establecimiento de ciertas normas de uso de los jardines, lo que implicaba a su vez un cierto grado de apertura al público. Estas normas se tallaban en piedra o se inscribían en alguna suerte de cartel a la entrada del jardín. Lo que él denominó lex hortorum (ley de los jardines) se basaba en el principio de que los jardines no se creaban solo para el disfrute personal de sus dueños sino para proporcionar placer a los amigos, haciendo partícipes a todo tipo de personas y al público en general, lo que rebajaba el concepto estricto de la propiedad privada. No entraré en la cuestión del uso público de estos jardines privados porque exigiría una investigación más profunda, pero este es un asunto muy debatido y debe observarse que se mezclan dos conceptos que no son antitéticos (como muchas veces se pretende hacer ver): por lo que sabemos, en muchas épocas se ha permitido un uso más o menos abierto y público del jardín frente al exclusivo y excluyente de los propietarios, aunque lo público con un estatuto jurídico equiparable a lo privado, solo comienza a aparecer a partir de la Revolución Industrial. Por lo demás, conviene no entusiasmarse en exceso: el hecho de que algún jardín dispusiera de estas leges o que se abriera al público en cierto modo, por interesante que sea, no indica que fuera una actitud general, ni en todos los casos, ni en todos los momentos. Se hace necesaria una comprobación mucho más minuciosa de la que Coffin proporciona y que debe tener en cuenta una amplia iconografía y numerosos ejemplos de jardines, muchos de los cuales ya han desaparecido y solo se conocen por referencias. El texto de Erasmo parece permitir dos deducciones: primera, que no parece que esta apertura parcial de los jardines se limitara a Italia sino que podía ser común a todo el continente; segunda, y significativa en el estudio de las leges hortorum,

28. Coffin, D. R., "The lex hortorum and access to gardens of Latium during the Renaissan ce". Journal of Garden History, vol. 2, 3, pp. 201232. 
que Eusebio recalca que los extraños solo podían acceder al jardincillo exterior y no al más lujoso y cuidado del interior de la casa ${ }^{29}$.

El ejemplo más antiguo que presenta Coffin es el de Vigna Carafa (1510). Ya el nombre nos avisa de que puede tratarse de un espacio algo distinto del locus que estamos estudiando: resulta indicativo que el espacio se denomine vigna y no orto, porque la primera bien pudo ser una especie de viñedo-huerto mientras que el segundo fue en la Italia renacentista un jardín de carácter auténticamente ornamental como los grandes espacios cardenalicios o papales de la época. Pero tampoco este extremo aparece suficientemente aclarado: en realidad no sabemos con precisión de qué tipo de espacio plantado estamos hablando. Coffin trae a colación otros ejemplos, aunque son relativamente tardíos y tampoco muy detallados. Por ejemplo, hablando de un jardín trasero al palacio romano del cardenal Giuliano Cesarini, señala que poseía una inscripción en la diaeta statuaria, es decir, en la construcción que servía de albergue a las estatuas, no en los jardines. El propio Coffin propone como jardín más significativo que dispuso de su lex horti el patio de las estatuas del cardenal Andrea della Valle en el centro de Roma, a partir del 1520. Fue el propio cardenal el responsable de ampliar la apertura del patio a "todos los romanos y visitantes".

Aunque el término pueda parecer explícito, podemos afirmar que el sentido de estas leges hortorum no está suficientemente definido: no se sabe con precisión qué marcaban, sugerían o prohibían estas leyes. De los ejemplos anteriores y algún otro, Coffin aporta algunos lemas; su lectura permite concluir que se trata solo de "placas conmemorativas" o expresivas acerca del motivo existencial del lugar. Sin embargo, Coffin insiste en que el término responde a la idea de un comportamiento especial que debía regir la presencia de los visitantes en los jardines. Sin entrar a valorar en detalle la existencia, difusión y uso de estas leges, parece posible afirmar sin embargo que, efectivamente, existieron y que debieron aplicarse en algunos jardines. En apoyo de esta afirmación podemos estudiar el ejemplo bien notable que se encuentra en el Convivium religiosum.

Cuando Eusebio acompaña a sus invitados a entrar en su casa, comenta que, mientras preparan la ensalada en la cocina, pueden dar "un paseo para ver los jardines" (673A). Timoteo pregunta si acaso hay otros aparte del que ven: porque en ese momento, ante la puerta principal de la casa, se encuentran, en efecto, en una especie de antepatio, zaguán o atrio ajardinado "con un aspecto agradable que saluda cuando uno entra y le da la bienvenida" (673A). Por lo

29. He señalado este aspecto de la apertura al público en Páez de la Cadena, F. "El ideario del jardín renacentista", en Domínguez Garrido, U. y Muñoz Domínguez, J., coords. "El Bosque" de Béjar y las villas de recreo en el Renacimiento, Actas de las III Jornadas, Béjar, 2000, y en Páez de la Cadena, F., "Del paraíso terrenal al parque público del siglo XXI. Una aproxima ción a la idea de jardín". Berceo, n 167, 2014, pp. 209238. 
que señalan los comensales no es muy grande pero en cambio tiene alguna cosa destacable. Una de ellas señalada por Timoteo, es que "San Pedro guarda las puertas" (673A) y otra, resaltada por el propio dueño es que ese San Pedro que actúa de portero "no es mudo, porque te habla en tres lenguas" (673A).

Los invitados leen las palabras escritas al lado de Pedro en tres idiomas distintos: latín, griego y hebreo. Y a continuación Eusebio explica a sus invitados lo que aquello significa. Las palabras en latín dicen: "Si quieres entrar en la Vida, guarda los mandamientos"; el texto griego indica "Arrepiéntete y conviértete" y el hebreo que "el justo vivirá en la Fe" (673B). Para beneficio de sus amigos, Eusebio ofrece una interpretación de las palabras de Pedro: "Menudo portero sin modales que, en un primer momento, nos ordena liberarnos de nuestras iniquidades y aplicarnos al servicio de la Divinidad, que luego nos dice que la salvación no llega por la Ley mosaica sino por la Fe del Evangelio y, para terminar, que la vía a la Vida eterna se consigue con la observancia de los preceptos evangélicos" (673B).

Obsérvese que las tres lenguas están en orden inverso a su antigüedad (en relación con el texto bíblico) y que, en cambio, pueden interpretarse sus mandatos en un orden de menor a mayor dificultad de lectura y de aplicación. Porque el primero exige vivir acorde con los principios primigenios del Antiguo Testamento, mandamientos que son "ley antigua" para Erasmo. El segundo mandato es más preciso y personal: es cosa de cada cual arrepentirse y convertirse y conviene notar que este imperativo conlleva dos acciones y un cambio de disposición: cada cual debe mirar en su interior, comprender qué mal ha hecho y arrepentirse de él. Esta contrición supone también la conversión a una nueva manera de ser y de vivir: se trata, por tanto, de un cambio interior que remoza por completo al individuo que lo experimenta, lo que adecua su comportamiento al tercer mandato: el justo, el que se comporta como es debido y obra con arreglo a la ley de Dios, es el que tiene verdadera fe y, por ello, puede vivir en ella.

En mi interpretación, y en aplicación de su philosophia Christi, Erasmo coloca en orden creciente de importancia los mandatos que imparte el guardián de ese pequeño jardín. Es fácil comprender el mandato en latín e, incluso cumplirlo, pero el mandato hebreo, el originario, que exige al creyente creer con la Fe que Yahvé exigió a su pueblo (que le traicionó construyendo el becerro de oro) o que Jesucristo pidió a sus apóstoles (que le traicionaron durmiéndose o, como Pedro, renegando de él), es enormemente más difícil de leer (no todos los presentes son capaces de hacerlo) y de ponerlo en práctica. Este es el tema principal del diálogo, como ya se ha visto, y es el principal reproche que se hace a la religión tal y como Erasmo la conoció en su tiempo o la padeció en el internado: el cuidado extremo y ridículo de ritos y formas y el descuido del venero auténtico de la creencia. Erasmo presenta a Pedro con sus leges escritas, evocando su papel de portero del Paraíso, dándole las Ilaves (las claves, los mandatos) que permitirán el ingreso en la vivienda y, por añadidura, en los jardines interiores cuya existencia afirma Eusebio pero que los invitados todavía no conocen y que no es posible 
ver ni disfrutar desde el exterior. He aquí cómo la dificultad de lectura de cada lengua conlleva también un nivel mayor de exigencia en la vivencia del cristianismo: he aquí también cómo la lengua más antigua, quizá la que puede tomarse entre las tres como la lengua sagrada por antonomasia, es la que ofrece el mandato más exigente, más completo, más moderno.

Este conjunto de leges podría considerarse un capricho de Erasmo pero en mi opinión no hay duda de que tiene un sentido admonitorio y explicativo en el conjunto de su diálogo. Su papel es tanto más significativo cuanto que no es el único conjunto de leges que se presenta a los visitantes de Eusebio. La estatua de Pedro lo muestra señalando hacia una capillita adjunta, abierta, con un altar en el centro del cual, como dice Timoteo, "está Jesucristo mirando a los Cielos y señalando con su mano derecha hacia Dios Padre y el Espíritu Santo, y con la izquierda parece dar la bienvenida a los recién llegados" (673B). Eusebio les hace ver que tampoco esta imagen está muda: otras tres inscripciones en latín, griego y hebreo requieren la lectura e interpretación de los amigos. "Yo soy el camino, la verdad y la vida", "Yo soy el alfa y el omega" y "Venid, hijos míos, os enseñaré el temor de Dios".

Quien habla ya no es portero de los cielos: es el mismo Jesucristo. Y en orden creciente de importancia proceden sus palabras también: primero se define a sí mismo, proporcionando el ejemplo inmediato para el creyente; después se define frente al mundo (es principio y final, nada hay que no sea por referencia a Él) y, finalmente, se define respecto a su propio padre, es decir, como Hijo de Dios: es él quien sabe quién y cómo es verdaderamente el Padre y cómo el hombre debe comportarse ante él para conseguir la vida eterna.

Esta segunda lista de mandatos o leges parece, en mi opinión, confirmar la primera e insistir en la línea que el cristiano ha de seguir para Ilegar a Dios. Creo que la philosophia Christi de Erasmo está resumida en estas frases que sirven de acogida a los comensales, de mandato para sus vidas y de introducción a las ideas que luego se expondrán en el convivio. Me parece interpretar también que los primeros mandatos escritos y transmitidos por Pedro podrían calificarse de preceptos éticos generales: son movimientos individuales, del alma de cada uno de los presentes. Exigen la puesta en marcha de una voluntad individual y de una acción personal para ejercer ese "deber ser". Si uno quiere Ilegar a la Vida hay que guardar los mandamientos; debe arrepentirse y convertirse; debe creer. Por el contrario, las segundas leges, impartidas por el mismo Jesucristo, presentan un cariz teológico y soteriológico. Supuestas la conversión y la creencia, es Jesucristo quien nos invita a llevarnos directamente al Cielo; no es ya un movimiento de la voluntad sino una materialización de la gracia divina: es el camino, la verdad y la vida, fuera de él no hay nada (es alfa y omega) y solo con Él (recuérdese, la doctrina de Erasmo es "filosofía de Cristo", en eso consiste ser de verdad cristiano) es el único capaz de introducirnos al auténtico conocimiento de Dios y a la única salvación posible. Este contraste o complementariedad entre los dos grupos de leges resume, en mi opinión, el sentido de la religión para Erasmo. El creyente debe hacer lo necesario para ponerse en disposición; pero solo eso no 
basta. Es imprescindible que Dios preste su ayuda mediante la intervención de su Hijo; y, como es natural, esta manifestación soteriológica escapa a nuestra voluntad porque solo nos cabe esperarla de la bondad divina.

Es inevitable evocar aquí la idea luterana de la salvación por la sola gratia; esta es imprescindible pero para Erasmo no parece bastar: las leges están organizadas en dos grupos que han de leerse (y ponerse en práctica) de modo sucesivo. La gracia aparece en un segundo término (el segundo grupo) una vez que el individuo ha puesto de su parte para llegar a su salvación; ha de ser el individuo quien ejecute las obras, quien aporte su esfuerzo para conseguir llegar a la Fe. Erasmo viene a decir, según creo, que para llegar a la Vida es necesario seguir ambas grupos de leges. Ni la intervención divina per se ni la sola disposición anímica en el hombre son suficientes para alcanzarla: ser un buen cristiano y llegar al paraíso prometido exige el cumplimiento de esos dos mandatos, uno tras otro, en el jardín de entrada. Solo así se garantiza el acceso al jardín prometido que está oculto en el interior.

Finalmente, y teniendo en cuenta que el diálogo desarrolla algunos aspectos fenomenológicos interesantes en relación con el bienestar corporal y anímico, me parece importante también la intuición de que tras la exposición de estas leges escritas se esconde una dialéctica del sentimiento interior en relación con el desplazamiento. Los invitados entran al jardincillo, leen las primeras normas, y avanzan hasta el altar, donde reciben los mandatos definitivos, los más actuales: solo entonces, y tras rezar una breve oración, podrán ingresar en la casa y en los auténticos jardines. Aquí, los movimientos físicos acompañan a los movimientos del alma, como la disposición anímica de Fedro y Sócrates se logra con la salida al campo, el disfrute del vientecillo que sopla en el lugar y del agua fresca en los pies. Eusebio señala también que ese jardincillo de acceso está abierto a todos los paseantes y que atrae a muchas personas, que suelen decir una jaculatoria movidos por las leges que ven escritas. Dicha esta, señala a sus convidados "que ya es hora de ver este jardincillo cuadrado que está tapiado y que es mejor que el otro" (674A). Es este un jardín diseñado como lugar de placeres, "honestos", como ya hemos visto que matiza Eusebio y en el que Timoteo cree ver los jardines de Epicuro: a un tiempo lugar de sabiduría y de goce. Una progresión que admite a los presentes a un lugar de delicias todavía no visto, mucho mejor que el pequeño jardín exterior, un lugar dedicado a los placeres corporales que disponen a la beatitud del ánimo y a la reflexión filosófica en compañía de amigos. Creo que así puede verse cómo el papel de estas leges es esencial a la comprensión del diálogo y cómo por ellas podemos también entender que los jardines de Eusebio no son meramente circunstanciales. Sin ellos, por el contrario, el diálogo erasmiano que pretende transmitir y divulgar los rasgos de su philosophia Christi y plantear un nuevo modo de entender el cristianismo sin dejar de volver una mirada llena de interés hacia el mundo pagano antiguo y al momento histórico de su presente quedaría desvirtuado y vacío: literalmente, en el caso de este jardín de ingreso, el ser humano se quedaría fuera, sin acceso posible. 